\title{
THE DEVELOPMENT OF COMPUTER-BASED TEST (CBT) BASED ON HYPERTEXT PREPROCESSOR (PHP)
}

\author{
Baharuddin J.H. ${ }^{1)}$, Indri Astuti ${ }^{2)}$, Aloysius Mering ${ }^{3)}$ \\ ${ }^{1)}$ Universitas Tanjungpura, Pontianak, Indonesia \\ E-mail: sendtobahar@gmail.com \\ ${ }^{2)}$ Universitas Tanjungpura, Pontianak, Indonesia \\ E-mail: indribk91@yahoo.com \\ ${ }^{3)}$ Universitas Tanjungpura, Pontianak, Indonesia \\ E-mail: mering7157@yahoo.co.id
}

\begin{abstract}
This study aims to produce design, to know the profile and to determine the level of effectiveness of the Hypertext Preprocessor (PHP) based on Computer-Based Test (CBT) to Test of English For Academic Proficiency (TEAP) IKIP PGRI Pontianak. The development research method is the ADDIE development design model. The research subjects were students of the eighth semester English study program and the lecturers and staff who served at UPT Bahasa of IKIP PGRI Pontianak. Data collection tools used interviews and TEAP user questionnaires then analyzed with the formula from Khabibah. PHP-based CBT profile in the form of a web that can be accessed online and integrated with multiple-choice item analysis. This study found that TEAP requires a system that can automatically be correcting, storing test results, analysing test results and distributing test certificates. The results showed that the effectiveness level of the respondents' opinion of the test participants with a percentage score of $77 \%$ in good category and from the opinion of respondents who implement TEAP is very effective and can analyze the level of difficulty, difference power and distractor analysis properly and quickly. This illustrates that PHP-based CBT is suitable for the TEAP program.
\end{abstract}

Keywords: ADDIE Model; Computer-Based Test; CBT; PHP

\section{INTRODUCTION}

Today's millennial generation familiar with technology and information that affects many aspects of life, one of them is education. The development of the Computer-Based Test (CBT) has changed from the conventional test pattern by using paper to a computerized system. In this era, students are required to be accustomed to using $\mathrm{CBT}$ for example, the National Examination (UN) known as the Computer-Based National Examination (UNBK), the Higher Education Entrance Selection is known as the Computer-Based Writing Examination (UTBK), the CPNS Acceptance Test, TOEFL and so on. The researcher interested to develop CBT based on Hypertext Preprocessor (PHP) which can be used by students in preparation for this millennial generation test pattern.

The test to be developed is in the form of a multiple-choice test consist of multiple-choice item analysis as a reflective material for educators to improve the quality of education. The main key to improve the quality of education lies in the learning process and educators which play an important role including in conducting assessments.

The results of research conducted by Muhson et al. (2013) also found that from 65 educators, there are only $11 \%$ (7 people) always performed item analysis while $11 \%$ ( 7 people) and $78 \%$ never did item analysis (51 people) have only conducted item analysis but not routinely, generally only did item analysis because it was demanded by the supervisor. This means that educators' awareness in analyzing the items is still lacking. Researchers conducted interviews with several lecturers at IKIP PGRI Pontianak who also gave the same statement that they rarely did item analysis on the grounds because they have lack of time to do it.

Assessment is the most important thing in learning (Russell \& Airasian, 2012: 2). Assessment is very important in improving the learning process (Raymond et. al., 2012; Bers, 
2008: 32). Therefore, educators must have adequate skills in conducting the assessment. Assessment can maintain class balance, plan or implement learning, group students, provide feedback, reward, diagnose problems, and assess the level of academic progress (Russell \& Airasian, 2012: 5-8). The assessment will produce the right information if the instrument used to take measurements meets several criteria such as validity, reliability, and objectivity (Anderson, 2003: 10; Kubiszyn \& Borich, 2013: 326). Item analysis is an important part of ensuring the validity of the questions to be tested (Nunnally \& Bernstein, 1994: 304). Thus educators must be able to master the concept of item analysis along with analyzing the items and familiarize themselves with doing tests with today's test patterns.

Based on the importance of the assessment, it is necessary to develop a question analysis software that is easy and applicable to motivate educators to do item analysis. There are many item analysis software developed by experts but rarely are integrated with existing tests and the existing software has not been used optimally by educators. This happens because most of the software is in foreign languages and stands alone without integration with the CBT application, making it difficult to understand how to use it and having to re-enter test results that have been carried out, resulting in a long process and time.

Based on this background, the researcher raised the title "The Development of Computer-Based Test (CBT) based on Hypertext Preprocessor (PHP)" which will be integrated with multiple-choice item analysis then to find out the right design, to know the profile and the effectiveness level of the Computer-Based Test (CBT) based on Hypertext Preprocessor (PHP) to Test of English For Academic Proficiency (TEAP) IKIP PGRI Pontianak.

\section{Methodology}

This research refers to the design of Research and development (R\&D), which means that the research method used to produce a product and then test the effectiveness of the product. The product to be developed from this research and development is in the form of a computerized test or what is known as a PHP-based Computer-Based Test (CBT) which can be used by educators as administrators and students as users or users on the Test Of English For Academic Proficiency (TEAP) which was implemented by the UPT Bahasa of IKIP PGRI Pontianak.

The subjects in this study were divided into two, namely the subject of development and the subject of product testing. The subject of development is an expert judgment to measure the feasibility of the program in terms of design, material and appearance and function of the program. Design experts were Dr. Aunurrahman, M.Pd and M. Iqbal Ripo Putra. Material experts were Finny Anita, M.Pd and Citra Kusumaningsih, M.Pd while media experts were Vindo Feladi, ST., M.Pd and Ratih Widya Nurcahyo, M.Pd. the validators were lecturers of IKIP PGRI Pontianak based on their expertise. The product trial subjects were students of the eighth semester of the English language education study program as well as lecturers and staff assigned to the UPT Bahasa of IKIP PGRI Pontianak.
This research procedure follows the steps of research and development of the ADDIE design model, the selection of the ADDIE model is based on (Pribadi, 2018: 43) the systematic and systemic implementation of the ADDIE model will ensure the creation of an effective and efficient training program, as for the steps The first thing to do is analysis. At the stage of the analysis carried out, namely the needs analysis of TEAP, literature analysis and analysis of situations and conditions so that during the Covid-19 pandemic, TEAP can still be carried out according to health protocols.

The TEAP implementation consists of 140 multiple choice questions with a total time of 115 minutes which is divided into three parts consisting of 50 questions in 35 minutes of listening, 40 of structures and written expressions in 25 minutes, and reading (reading) as many as 50 questions in 55 minutes. The implementation of TEAP starts with listening, listening questions are in the form of audio that cannot be repeated, so in this development, it must accommodate audio playback without being able to be repeated, then continued with structure, written expressions and reading.

The next stage is designing the process of running the TEAP application by making an initial design in the form of a flowchart and data flow along with the database design used. In the development process, namely turning the design into a draft product that will be tested by experts, then testing small groups, medium groups and large groups. After going through the trial phase and making revisions according to the input, then it is implemented to test participants and test administrators, the results are evaluated, at the evaluation stage the researcher wants to know the effectiveness of PHPbased CBT for TEAP implementation according to the opinion of respondents who use TEAP.

The instruments used in this study consisted of a questionnaire, observation sheet (interview guide), and a questionnaire for TEAP users. Data analysis was carried out qualitatively and quantitatively. Qualitative data were analyzed using descriptive statistics, while quantitative data were analyzed using the formula from Khabibah to determine the effectiveness of PHP-based CBT in TEAP according to TEAP user responses.

\section{RESULTS AND DISCUSSION}

\section{A. Results}

The research results will be presented based on the ADDIE instructional system design consisting of Analysis, Design, Development, Implementation, and Evaluation. The following is a description of the research results:

1. Analysis

A systematic process for determining objectives, identifying mismatches between feasibility and desired conditions, consisting of literature review, observation and preparation of initial reports. Initial research through observations of real field conditions. In this research, the analysis stage was carried out by observing and interviewing the UPT Language managers about the need for evaluation, especially in the use and development of CBT. Then the researcher collected and read literature on 
programming language, determined the right programming language for PHP-based CBT development, data storage or database types to be used in the development, needs of educators especially evaluation needs, the student needs especially in the use of CBT, data collection about analysis students undertaken to find out the characteristics of students and collect literature studies on the problem/research to be carried out.

2. Design

An important step taken in the design stage is how an instructional designer can provide an overview of the product to be made. In this study, data flow, display design, and database were created. In the data flow using a flowchart and for the display design section, the researcher uses the Balsamiq Wireframes application to compile the storyboard, and the database uses MYSQL.

3. Development

The development of the initial product format from the flowchart and storyboard will be coded using PHP, after being coded then prepared the database using MYSQL as a data store or database, then testing will be carried out to see the system results, and debugging to see the error-free system and testing experts, namely design expert validation, material expert, media expert and then after the validation process, the product is revised based on comments, suggestions and input from design experts, material experts and media experts.

4. Implementation

In the implementation stage, the product is ready for use after going through tests from experts, they are design experts, material experts and media experts. In this trial and revision stage, it is carried out with three stages of testing and three stages of revisions, as follows:

a. One to One trial (small group)

After the validation stage, the activity carried out is a one to one trial which is carried out to assess the products developed according to the characteristics of students. This one to one trial was conducted on one lecturer who is experienced in using CBT and 3 students.

b. Revision

After a one to one trial is carried out, the product will be revised. Researchers made revisions by considering the input provided by the lecturers and students who conducted the first stage trial.

c. Small Group Trial (medium group)

After the PHP-based CBT was revised, the next trial was carried out, namely a small group trial involving 2 lecturers and 6 students in the class.

d. Revision

After the small group trial, the product revised. Similar to the previous trial in this second revision, the researchers also considered the input provided by research subjects in the product improvement process.

e. Field Test (large group)

After the PHP-based CBT revised, the next trial conducted by involving 3 lecturers and 20 students. The field test is the final testing phase.

\section{f. Revision}

After the field test was carried out, the final stage revision was carried out to obtain the final product from PHP-based CBT.

\section{Evaluation}

Evaluation of the final product of CBT based on PHP based on suggestions and field trials. In this case, the researcher evaluates the effectiveness seen from the user opinion of the PHP-based CBT product (36) thirty-six students with the results can be seen in Fig. 1.

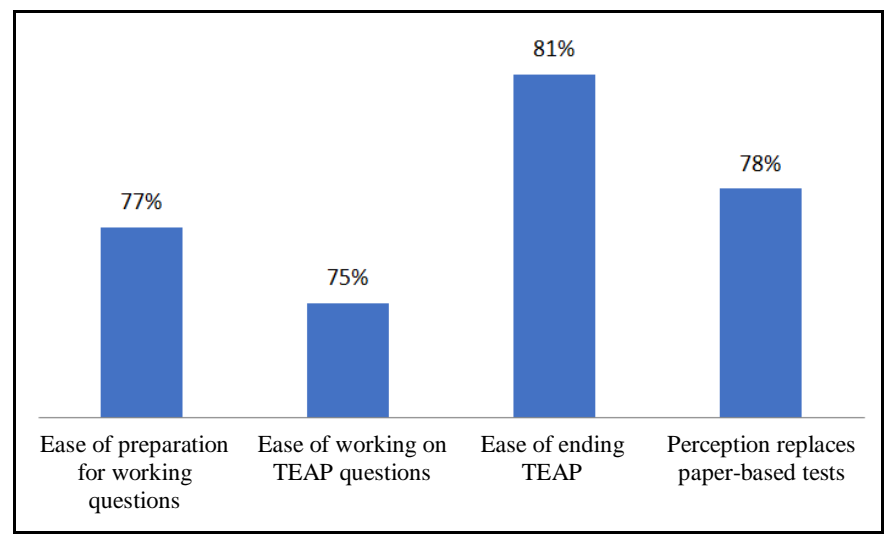

Fig. 1 The Effectiveness based on respondents' opinions

Test takers' perceptions of the effectiveness of PHP-based on CBT in implementing TEAP were in good categories, both in terms of the ease of starting the test $(77 \%)$, the test process $(75 \%)$ to ending and seeing the test results $(81 \%)$. This perception is also indicated by the respondent's opinion on the question item on the perception of how good the PHP-based CBT application is for the TEAP program to replace conventional tests using the paper-based test, the respondent's opinion shows that $40 \%$ (forty per cent) of respondents gave a good perception, while 19\% (nineteen per cent) had very good perceptions and the others responded quite well

\section{B. Discussion}

PHP-based CBT development research built to make it easier to do the Test of English for Academic Proficiency (TEAP). TEAP is a new program from UPT Bahasa of IKIP PGRI Pontianak which is intended as a requirement for all students who will take their thesis to be able to do an English/TOEFL prediction test both online and offline at UPT Bahasa of IKIP PGRI Pontianak.

This application is expected to streamline test implementation, both in terms of implementation, correction, assessment, distribution of certificates, question analysis, answer analysis and can save time and money. The TEAP which will be developed is also expected to replace conventional tests/paper-based tests considering that in the Covid-19 pandemic conditions and the TEAP test results are also archived or stored in the database.

\section{1) CBT Design based on PHP}

Development design is an initial design to obtain important information needed before carrying out development activities. 
In this study, the development design model is classified as a system-oriented learning model. According to the learning model according to from Gustafson and Branch (2002) which states that there are three learning design models, namely (1) Classroom-oriented models, (2) product-oriented models, and (3) system-oriented models. In this research, the development design used is system-oriented models. There are several developer design models in system-oriented models, one of which is ADDIE (Analysis, Design, Development, Implementation, Evaluation) which is a development design used in this study. The ADDIE model is used in this development because the ADDIE model is suitable for training programs according to Pribadi (2018) in line with research conducted by Rendy et al. (2015) to develop computer-based test software (CBT-Software) also using the ADDIE development model in the development process, in the development of the Designing Computer-Based Summative Test conducted by Johan and Supardi (2019) also used ADDIE in the development process.

The initial analysis carried out as a reference in the planning process of PHP-based CBT development at the Test of English For Academic Proficiency (TEAP) Training carried out a needs analysis from the test taker to the needs of the test takers. The need for test administrators, namely PHP-based CBT that was developed can accommodate the running of tests during the Covid-19 pandemic safely by paying attention to the Covid-19 protocol standards, so in development, a scheme must be made so that the test can be carried out with the facilities owned by test takers, one of which is a smartphone and laptops owned by test takers. Based on these considerations, a programming language was chosen that can accommodate all types of operating systems and all types of devices.

The millennial generation and Industrial Revolution 4.0 nowadays, smartphones and laptops are needs, so the selection of programming language used in this development must accommodate it to be accessed by smartphones and laptops, so the Hypertext Preprocessor programming language was chosen, previously called Personal Home Pages (PHP). From the test taker's side, it is also considered how the test taker does not have physical contact with the test taker, both in the distribution of questions to the distribution of the test result certificate, all from one device, namely through the test taker's smartphone/laptop.

The analysis carried out cannot be separated from the objectives of TEAP according to the TEAP procedure manual, which is to provide Test of English for Academic Proficiency (TEAP) services both from inside and outside the IKIP PGRI Pontianak. The TEAP implementation consists of 140 multiple choice questions with a total time of 115 minutes which is divided into three parts consisting of 50 questions in 35 minutes of listening, 40 of structures and written expressions in 25 minutes, 50 questions of reading in 55 minutes. The implementation of TEAP starts with listening, listening questions are in the form of audio that cannot be repeated, so in this development, it must accommodate audio playback without being able to be repeated, then continued with structure and written expressions and finally reading.
An important step taken in the design stage is how an instructional designer can provide an overview of the product to be made. The researcher analyzed the objectives of TEAP, TEAP questions to be used, TEAP implementation procedures, TEAP flowchart design, data flow, and TEAP storyboards. The data flow uses a flowchart, the storyboard design section uses the Balsamiq Wireframes application, and the database uses MYSQL.

The development process is a process of changing from a concept/design to a product, researchers change from flowcharts and storyboards to test applications. This CBT product is a Server to Client application developed with the Hypertext Preprocessor (PHP) programming language with the MySQL database and for the interface using bootstrap.

This CBT application can be accessed via smartphone or laptop web browser with the URL: https://teap.ikippgriptk.ac.id which is a sub-domain of ikippgriptk.ac.id. The finished product draft then tested for validity by experts, in this study, the development team consisted of 6 expert teams consisting of two expert design teams, two media expert teams and two material expert team. Selection of the expert team through several considerations including validating experience, the suitability of educational background, and teaching history so that the right expert team can be determined.

The results of the design expert's validation on the appearance of test administrators and test-takers are very feasible so that the PHP-based CBT developed is very feasible in terms of appearance and completeness of the menus in the application. The results of the design expert validation provide very feasible criteria for the design of the PHP-based CBT application after revision is made according to the input of the experts, namely by increasing the security side of the application by adding scrip so that it cannot do multiple logins. The results of the material experts on the relevance aspect show very feasible criteria, this illustrates that PHP-based CBT is very feasible both in terms of its relevance to the material, the accuracy of the application for correcting answers and giving a final score, and the completeness of the facilities is considered very feasible because it supports giving weight to the test as well as the remaining test time that can be easily seen by test takers.

The results of the media experts on the display aspects of the educator interface show proper criteria, this illustrates that PHP-based CBT is very suitable for use in TEAP. After going through the expert validation stage, trials are carried out in small, medium and large groups, the three stages of the trial will be revised according to the test results.

The small group trial involved one lecturer and three students of the English Education Study Program of the IKIP PGRI Pontianak. From the educator interface, there is no improvement in this trial, all functions work well, but the student interface experiences audio problems that keep playing when the question displayed, and the Reading question constrained by the line in question that does not match the line because of the display on the CBT is different with the paper/hardcopy questions. Based on these problems, 
revisions were made according to the feedback given by the research subjects.

The medium group trial involved two lecturers and 6 students, the results of the group trial were participants had difficulty in working on reading questions because of the revised reading text/questions confused them and they had to scroll up and downward while reading, enter each line and make the text a length especially on the display on a smartphone, then a revision is made by correcting the question. After being revised, the results of the large group trials showed that the system was ready to use without revision.

\section{2) The Profile of PHP-Based CBT}

PHP-based CBT is an application developed for multiplechoice tests equipped with item analysis. It is specifically for the Test of English For Academic Proficiency (TEAP) held by UPT Bahasa of IKIP PGRI Pontianak for the students who will pass/take their thesis.

PHP-based CBT was developed with two user levels, namely test takers and test-takers. For user convenience, both user levels can log in with one login interface, by browsing using a web browser with the URL address https://teap.ikippgriptk.ac.id. Based on Radhika's opinion (2019) that security and comfort in the IT world are inversely proportional, which means that even though it can be done in one interface for the convenience side, and the security side a captcha code is needed, on PHP-based CBT using the summation captcha at each login to avoid hacking brute force robots and to avoid sniffing/theft of PHP-based CBT login data using secure socket layer (SSL). Meanwhile, for the security of the test implementation so that other people cannot help it and ensure that the user and password for the test can only $\log$ in on one device, they are given an anti-multiple login script in their login session.

The test implementation process can be done using the participant's device, either a laptop or smartphone connected to the internet network. The test taker can start the test after receiving a starting code from the supervisor after the code is entered it means the test has started and the test execution time will appear on the test taker's screen. If the test taker does not end the test until the time runs out, the test will automatically end and the test score will come out along with the test certificate. The test results will be recorded as a tested history which will then be used as material for analyzing the items by the test administrator. Analysis of the items to determine the weaknesses and strengths of students for improvement in teaching, especially in English lessons.

\section{3) The Effectiveness of PHP-Based CBT}

The effectiveness of PHP-based CBT is seen from the opinions of respondents who use the TEAP application. According to the opinion of Sugiyono (2017: 407), R\&D is a research method used to produce certain products and to test the effectiveness of these products.

Respondents who administered the test gave the impression that the PHP-based CBT developed was very effective in terms of ease, speed and accuracy in correcting test results in providing test scores. Test results can be archived in this developed PHP-based CBT system so that it is easy to view the test history and perform test item analysis. UPT manager. The language also appreciates PHP-based CBT because the application built can be developed according to the needs of the manager, such as the format for reporting is already available in this application and the data can be exported into excel so that it is easier to use for other purposes.

This result shows that PHP-based CBT developed with the ADDIE model has a good effect and can be accepted by both administrators, administrators and test-takers. In line with research conducted by Firdaus (2019), a service, especially information services, should have an element of effectiveness to be accepted by its users, not only to be accepted but also to meet user needs.

\section{CONCLUSIONS AND SUGGESTIONS}

\section{A. Conclusions}

The development design in this study uses a systemoriented learning model, the ADDIE Model. Based on this model at this stage of the analysis, the researcher pays attention to the needs analysis and the literature study. While in design stages, the researcher explains the planning and product design in the form of PHP-based CBT to be developed.

The stages of developing PHP-based CBT for the Test of English for Academic Proficiency (TEAP) which was carried out by UPT Bahasa of IKIP PGRI Pontianak began with realizing the design that had been designed previously to become the initial product of PHP-based CBT. Researchers were concerned about step by step in making products. Since that PHP-based CBT must be able to run following the design and can be easily accessed by users. The developed product draft is then validated by experts, including media experts, design experts and material experts. This was done to obtain a feasibility assessment, as well as to get suggestions and comments for improvements to the PHP-based CBT design. Furthermore, the researchers conducted field trials to obtain a more contemporary response to PHP-based CBT. This trial was carried out in stages, first carried out by a one to one trial, second followed by a small group trial and finally a field test.

The results obtained from the validation of media experts, material experts and design experts are then revised. Likewise with the results of trials and field input obtained from both the one to one trial scale, the small group trial and the revised field test.

PHP-based CBT profile is a web-based information system that can be accessed online and offline, equipped with item analysis. The effectiveness of PHP-based CBT developed with the ADDIE model has a good effect and can be accepted by both administrators, implementers and participants of the Test of English for Academic Proficiency (TEAP) at UPT. Bahasa of IKIP PGRI Pontianak and can replace the paper-based test.

\section{B. Suggestions}

The results of this study are expected to be used as study material to develop a Computer-Based Test (CBT) and the results of this study are expected to be used as a reference for 
future research in the context of problems related to Computer-Based Test (CBT). For further researchers, this information system can be developed so that it is not limited to multiple-choice tests, it can be developed for essay tests and so on. This PHP-based CBT can be integrated with other information systems both in its interface and database.

\section{REFERENCES}

Anderson, L.W. (2003). Classroom assessment: enhancing the quality of teacher decision making. New Jersey: Lawrence Erlbaum Associates, Inc.

Bers, T.H. (2008). The role of institutional assessment in assessing student learning outcomes. New Directions for Higher Education, 141, 31-39.

Firdaus, Khonita. (2019). Efektifitas Layanan Mobile Application "mLibrary" di Perpustakaan Universitas Gadjah Mada. http://journal.unair.ac.id/LN@efektifitas-layanan-mobile-application-“mlibrary"--di-perpustakaanuniversitas-gadjah-mada-article-11375-media-136category-8.html

Gustafson, Kent, L., \& Branch, Robert, Maribe. (2002). Survey of Instructional Development Models (fourth edition). New York: Education Resources Information Center.

Johan, Joni, Ikhsanudin \& Supardi, Iwan. (2019). Designing Computer-Based Summative Test For The Eleventh Grade Students. English Education Study Program, Language and Arts Education Department.

Kubiszyn, T., \& Borich, G.D. (2013). Educational testing and measurement: classroom application and practice. $10^{\text {th }}$ edition. Hoboken, NJ: John Wiley \& Sons, Inc.

Muhson, Ali., Lestari, Barkah., Supriyanto, Baroroh, Kiromim. (2013). Pengembangan software analisis butir soal yang praktis dan aplikatif. Jurnal Ilmu Pendidikan, 20(2).

Nunnally, J.C. \& Bernstein, I.H. (1994). Psychometric theory (third edition). New York: McGraw-Hill, Inc.

Pribadi, Benny A. (2018). 21 Konsep Esensial dalam Teknologi Pendidikan. Jakarta: PT. Dian Rakyat.

Radhika. (2019). Pengujian Scurity Web pada Sistem Informasi. Prosiding Seminar Nasional MIPATEK (EJournal).

Raymond, J.E., Homer, C.S.E., Smith, R. \& Gray, J.E. (2012). Learning through authentic assessment: An evaluation of a new development in the undergraduate midwifery curriculum. Nurse Education in Practice, 30, 1-6.

Rendy, Zilan Zalila, Fauzi Bakri, A. Handjoko Permana \& Dewi Muliyati. (2015) Pengembangan Piranti Lunak Tes Berbasis Komputer (Cbt-Software) Untuk Mata Pelajaran fisika SMA. Prosiding Seminar Nasional Fisika (E-Journal) SNF2015.

Russell, M.K. \& Airasian, P.W. (2012) $\underset{\text { th }}{\text { Classroom }}$ assessment: concepts and applications ( $7^{\text {th }}$ edition). New York: McGraw-Hill.
Sugiyono. (2017). Metode Penelitan \& Pengembangan Research \& Development. Bandung: Penerbit Alfabeta 